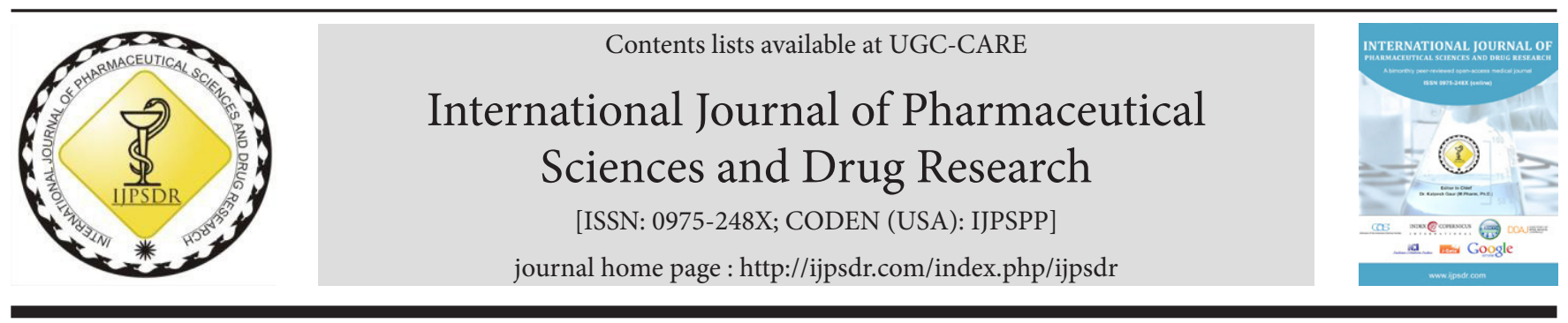

Research Article

\title{
Carboxymethylation of Karaya Gum: Application in Gastroretentive Drug Delivery for Sustained Release of Model Drug
}

\author{
Amit Verma ${ }^{1}$, Neetu Sachan ${ }^{2}$, Anurag Verma ${ }^{2^{*}}$ \\ ${ }^{1}$ Department of Pharmacy, MJP Rohilkhand University, Bareilly-243006, Uttar Pradesh, India \\ ${ }^{2}$ Department of Pharmaceutics, IFTM University, Moradabad-244001, Uttar Pradesh, India
}

\author{
ART ICLE INFO \\ Article history: \\ Received: 16 April, 2020 \\ Revised: 29 April, 2020 \\ Accepted: 08 May, 2020 \\ Published: 30 May, 2020 \\ Keywords: \\ Carboxymethylation, \\ Gelucire 43/01, \\ Hydrodynamically balanced \\ capsules, \\ Karaya gum, \\ Propranolol HCl. \\ DOI: \\ 10.25004/IJPSDR.2020.120314
}

\begin{abstract}
A B S T R A C T
Karaya gum (KG) is one of the least soluble of the gums. It does not dissolve in water to give a clear solution but instead absorbs water rapidly to form viscous colloidal sols. Carboxymethylation of karaya gum is expected to improve its aqueous solubility and gelling behavior. Another objective of the research is to evaluate the potential of carboxymethylated karaya gum (CMKG) as a drug release modulator (in acidic dissolution medium), when combined with hydroxypropyl methylcellulose (HPMC) K15M based polymeric matrices bearing propranolol $\mathrm{HCl}$ (PHCL). In the present study, KG was carboxymethylated using Williamson ether synthesis. Fourier transform infrared spectroscopy (FTIR) spectroscopy confirmed the formation of CMKG. The prepared CMKG was used in conjunction with HPMC K15M as a polymer matrix in the formulation capsule dosage form, using PHCL as a model drug. The filled capsules were then coated with gelucire 43/01 to convert them into hydrodynamically balanced (HBS) capsule dosage form. Dextrose and fructose were also added to the drug-polymer mix as osmogen to facilitate the drug release. The degree of substitution of CMKG was found to be 0.87 . HBS capsule dosage forms remained buoyant on $0.1 \mathrm{HCl}$ for up to 6 hours, the buoyancy was attributed to the gelucire 43/01 coating around the capsule shell. From the experimentation, it was observed that CMKG, when mixed with HPMC K15M at 1:3 ratios, extended the release of model drug from HBS capsule dosage forms in $0.1 \mathrm{HCl}$. At CMKG:HPMC K15M ratio 2:1, the release of PHCL from HBS capsules revealed fast drug release in $0.1 \mathrm{HCl}$. From the observations, it is evident that KG is amenable to carboxymethylation to form CMKG. It is also evident that it is advantageous to combine CMKG with HPMC K15M as release modulator to retard the release of PHCL in acidic dissolution medium.
\end{abstract}

\section{INTRODUCTION}

In recent years, the development and utilization of polymers isolated from natural sources have attracted increasing attention due to their sustainability, biodegradability, and biosafety. However, they evidence some drawbacks, such as variable chemical composition, uncontrolled rates of hydration, $\mathrm{pH}$-dependent solubility, poor mechanical strength when combined with other polymers, and high susceptibility to microbial attack. ${ }^{[1-3]}$ Chemical modification provides an efficient route not only for removing such drawbacks but also for improving swelling and solubilization. ${ }^{[4]}$ Because of their improved physicochemical properties chemically modified natural polymers have found numerous applications in drug delivery, biomaterials development, food and beverages, water purification, etc. ${ }^{[5-9]}$

Karaya gum is an anionic polysaccharide that has diverse applications, such as, suspending agents, emulsifying agents, bulk laxatives, dental adhesive, etc. It is a heavily acetylated acidic polysaccharide composed of $\alpha$-D-galacturonic acid and $\alpha$-l-rhamnose residues in the main chain with $0-4$ of the acid and $0-2$ of rhamnose linkages. ${ }^{[10]}$ As the polymer is heavily acetylated, it is least soluble among the other plant-derived gums.

\footnotetext{
${ }^{*}$ Corresponding Author: Dr. Anurag Verma

Address: Department of Pharmaceutics, IFTM University, Moradabad-244001, Uttar Pradesh, India

Email $\square$ : anuragverma_iftm@yahoo.co.in

Relevant conflicts of interest/financial disclosures: The authors declare that the research was conducted in the absence of any commercial or financial relationships that could be construed as a potential conflict of interest.

Copyright (C) 2020 Amit Verma et al. This is an open access article distributed under the terms of the Creative Commons Attribution- NonCommercialShareAlike 4.0 International License which allows others to remix, tweak, and build upon the work non-commercially, as long as the author is credited and the new creations are licensed under the identical terms.
} 
KG swells in water to yield highly viscous dispersions; however, these dispersions show a permanent loss in viscosity on heating. KG has diverse applications, such as, suspending agent, emulsifying agent, bulk laxative, and dental adhesive, and so on. KG has earlier been chemically modified by thiolation, ${ }^{[11]}$ dodecenylsuccinic anhydride derivatives, ${ }^{[12]}$ grafting, ${ }^{[13]}$ and deacetylation. ${ }^{[14]}$ However, there are no literature reports on carboxymethylation of KG in pharmaceutical literature and applications. Thus, considering the same, the present study was designed with the objective of synthesizing CMKG and evaluating its potential as a release modifying polymer for gastroretentive delivery of model drug PHCL. CMKG was synthesized by Williamson ether synthesis, and characterized by FTIR and differential scanning calorimetry (DSC) studies.

\section{Materials AND METhods}

\section{Materials}

The PHCL was obtained as a gift from Akums Pharmaceuticals, India. Gum Karaya was obtained as dry gummy exudate from Sterculia urens Tree. HPMC K15M was purchased from Central Drug House and Sigma Life Science, respectively. All other reagents were of analytical grade.

\section{Methods}

\section{Synthesis of CMKG}

The CMKG was synthesized from KG as per the synthetic procedure ${ }^{15]}$ with some modification. Briefly, KG (2 grams) was dispersed in $100 \mathrm{~mL}$ distilled water. After the gum was well dispersed, an appropriate volume of sodium hydroxide solution $(40 \% \mathrm{v} / \mathrm{v})$ was added, at a rate of $1 \mathrm{~mL}$ within 15 minutes, with continuous stirring at room temperature. An aliquot of $15 \mathrm{~mL}$ monochloroacetic acid was added to the reaction mixture over a period of 10 minutes. The reaction mixture was heated to $70^{\circ} \mathrm{C}$ with continuous stirring for 4 hours. The reaction product was repeatedly extracted with ethanol $(90 \% \mathrm{w} / \mathrm{v})$ and separated by centrifugation $(3,000 \mathrm{rpm}$ for 15 minutes at $4^{\circ} \mathrm{C}$ ). After the third extraction, the $\mathrm{pH}$ was adjusted to seven with glacial acetic acid. Finally, the precipitate was washed with water and dialyzed [dialysis membrane 1,000 kDa nominal molecular weight cut-off (MWCO, Sigma Aldrich, USA)] against distilled water for a couple of days (60 hours), and finally dried.

\section{Characterization of CMKG}

Both native and CMKG were characterized using FTIR, DSC, and X-ray diffraction.

\section{FTIR}

The KG and CMKG samples were subjected to FTIR spectroscopy in an FTIR spectrophotometer (PerkinElmer, version 10.6.0) in the range of 4,000 to $400 \mathrm{~cm}^{-1}$ as $\mathrm{KBr}$ pellets. Spectra were collected using a Perkin Elmer Spectrum One FTIR Spectrometer spectrophotometer (scan range $450-4,000 \mathrm{~cm}^{-1}$, resolution $1 \mathrm{~cm}^{-1}$ ).

DSC

The DSC thermograms of KG and CMKG samples were recorded using a differential scanning calorimeter (Q10 V9.0 Build 275, TA Systems, USA). About 7 to $8 \mathrm{mg}$ of sample were crimped in a standard aluminum pan and heated in a temperature range of 40 to $250^{\circ} \mathrm{C}$ at a heating rate of $10^{\circ} \mathrm{C}$ per minute with a nitrogen purge of $50 \mathrm{~mL} / \mathrm{min}$.

\section{${ }^{13}$ C Nuclear Magnetic Resonance (NMR) characterization}

The solid-state ${ }^{13} \mathrm{C}$ Cross Polarization Magic-Angle Spinning NMR (CP/MAS) NMR measurements were carried out on the $400 \mathrm{MHz}$ Varian solid-state NMR spectrometer at IIT, Roorkee.

The high-resolution ${ }^{13} \mathrm{C} \mathrm{CP} / \mathrm{MAS}$ NMR spectra were recorded at the resonance frequency of approximately $100 \mathrm{MHz}$ with the use of $4 \mathrm{~mm}$ rotors and MAS frequency of $12,000 \mathrm{~Hz}$ and $\pi / 2$ pulse duration of $1.9 \mu \mathrm{s}$. In the CP experiments, the Hartmann-Hahn condition was achieved with the radio frequency field strength of $58 \mathrm{kHz}$, a contact time of $1 \mathrm{~ms}$, and relaxation delay of 4 seconds between two consecutive scans. A high-power proton-decoupling field of $92 \mathrm{kHz}$ was applied during data acquisition. The spectra were obtained at room temperature averaging over 5,000 to 33,000 scans. The chemical shifts were referenced to the Tetramethylsilane (TMS) using adamantane as an external standard. ${ }^{[15]}$

\section{X-ray Diffraction}

Powder X-ray diffraction pattern of KG and CMKG were recorded employing X-ray diffractometer (Tabletop XRD, Miniflex 2, Rigaku, Japan). The sample powders were scanned from 0 to $80^{\circ}$ diffraction angle range under the following measurement conditions: source, nickel filtered $\mathrm{Cu}-\mathrm{K}$ radiation; voltage $30 \mathrm{kV}$; current $15 \mathrm{~mA}$; scan speed $0.05 \mathrm{~min}^{-1}$; division slit $1.25^{\circ}$; receiving slit $0.3 \mathrm{~mm}$.

\section{Determination of Degree of Substitution}

The degree of substitution was determined by classical acid wash method. ${ }^{[16-19]}$ In brief, freshly precipitated CMKG (0.5 grams) was dispersed in hydrochloric acid reagent $(20 \mathrm{~mL})$ for 3 to 4 hours, followed by filtration and washing with $70 \%$ methanol to remove the acid followed by drying to constant weight in an oven at $70^{\circ} \mathrm{C}$. The dried CMKG, so obtained, was well dispersed in $70 \%$ methanol, followed by the addition of an excess of sodium hydroxide $(0.5 \mathrm{~N})$ with stirring for 3 hours to dissolve the sample completely. The excess of sodium hydroxide was back titrated with hydrochloric acid $(0.5 \mathrm{~N})$ using phenolphthalein as an indicator. The degree of carboxymethyl substitution (DS) on KG was calculated using the following equation:

$$
\text { DS }=\frac{0.162 A}{1-0.058 A}
$$


Where $\mathrm{A}$ is the milliequivalent of sodium hydroxide required per gram of the CMKG sample.

\section{Preparation of HBS Capsules}

Single unit capsules were prepared by physically blending drug with the required quantity of polymer and other additives, as mentioned in Table 1, using double cone blender for 15 minutes. The powder mix was then encapsulated into hard gelatin capsules size 0 . The HBS capsule formulations were then dip-coated with molten gelucire $43 / 01$ maintained at $50^{\circ} \mathrm{C}$. The coated HBS capsules were immediately put into the refrigerator $\left(2-8^{\circ} \mathrm{C}\right)$ until further use.

\section{In vitro Buoyancy of Formulations and Drug Release Study}

In vitro buoyancy and drug release from HBS Capsules were evaluated simultaneously with a USP XXXI dissolution apparatus type II (paddle type, Electro Lab, Mumbai, India) at $50 \mathrm{rpm}$ in $900 \mathrm{~mL} 0.1 \mathrm{M} \mathrm{HCl}$ at $37 \pm 0.5^{\circ} \mathrm{C}$. At predetermined intervals, a $1 \mathrm{~mL}$ aliquot was withdrawn and replenished with an equal volume of fresh dissolution medium. The withdrawn samples were analyzed UV spectrophotometrically at $278 \mathrm{~nm}$. HBS capsule formulations that sank within the first hour were discarded from drug release studies.

\section{Results AND Discussion}

Gum karaya is the common name given to the dried exudation of the Sterculia urens tree. It is partially acetylated polymer of galactose, rhamnose, and glucuronic acid with an molecular weight (MW) of approximately 9,500,000. Carboxymethylation of polysaccharides is carried out by Williamson ether synthesis, in which the polysaccharide alkoxide is reacted with monocholoroacetic acid, and the primary and secondary alcohol groups are substituted by carboxymethyl group by an $\mathrm{S}_{\mathrm{N}} 2$ reaction. ${ }^{[18-20]}$

(Karaya gum)

$$
\mathrm{KG}-\mathrm{OH}+\mathrm{NaOH} \rightarrow \mathrm{KG}-\mathrm{ONa}+\mathrm{H}_{2} \mathrm{O}
$$

$$
\mathrm{KG}-\mathrm{ONa}+\mathrm{ClCH}_{2} \mathrm{COONa} \rightarrow \mathrm{KG}-\mathrm{OCH}_{2} \mathrm{COONa}+\mathrm{NaCl}
$$

The yield of synthesized CMKG was $78.65 \%$, and its appearance was off-white amorphous powder. The CMKG was characterized by FTIR and DSC studies. Fig. 1 shows the FTIR spectra of KG and CMKG in the frequency range of 4,000 to $400 \mathrm{~cm}^{-1}$.

KG displayed a broad absorption band at $3,459 \mathrm{~cm}^{-1}$ due to presence of $-\mathrm{OH}$ of galactopyranose and glucopyranose rings, a peak at $2,929 \mathrm{~cm}^{-1}$ corresponds to the $\mathrm{C}-\mathrm{H}$ stretching mode of $-\mathrm{CH}_{2}$ group, peaks at 1,730 and $1,620 \mathrm{~cm}^{-1}$ are due to $\mathrm{C}=\mathrm{O}$ stretching vibrations of free carboxylic acids and the methylated galacturonic acid esters of the gum. The absorption peaks between 1,041 to $1,153 \mathrm{~cm}^{-1}$ were attributed to $\mathrm{C}-\mathrm{O}$ and $\mathrm{C}-\mathrm{C}$ stretching vibrations of pyranose rings of KG. The absorption peak at $1,428 \mathrm{~cm}^{-1}$ was due to deformation vibrations of $\mathrm{CH}_{2}$ and $\mathrm{C}-\mathrm{OH}$ groups, and peaks at 1,300 to $1,200 \mathrm{~cm}^{-1}$ were due to $\mathrm{C}-\mathrm{O}-\mathrm{C}$ stretching vibrations. The above observation corresponds to the findings by Sethi et al. ${ }^{[21]}$

The spectra of CMKG (Fig. 2) shows a broad band from 3,459 to $33,435 \mathrm{~cm}^{-1}$ due to overlapping contributions of free and bonded $\mathrm{OH}$ groups of carboxylic acid. The peaks due to CO stretch of carboxylate ion appear at 1,641 and $1,412 \mathrm{~cm}^{-1}$, while the $\mathrm{CO}$ stretch of carboxylic acid appears at $1,080 \mathrm{~cm}^{-1}$. The bands at $1,025 \mathrm{~cm}^{-1}$ represented (C-O-C) stretching. The appearance of new absorption band at $1,563 \mathrm{~cm}^{-1}$ is suggestive of change in chemical environment brought by the carboxymethylation process.

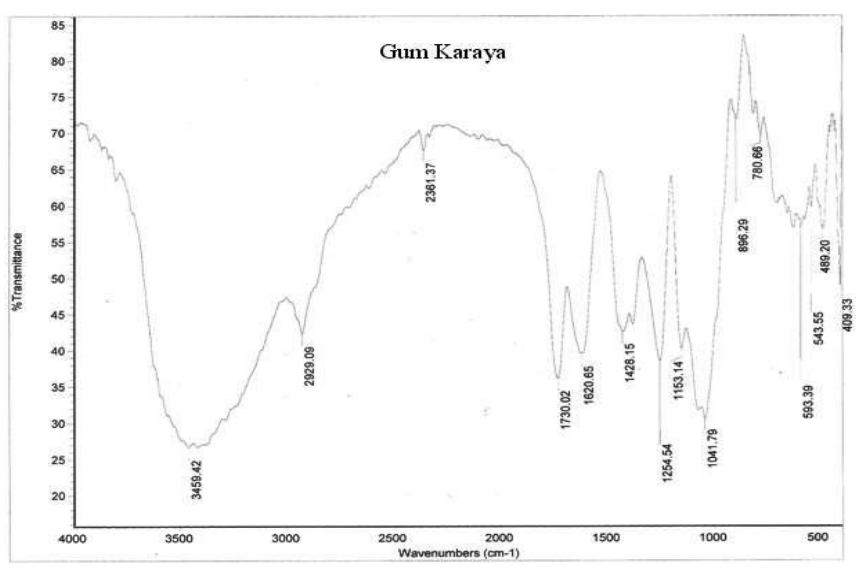

Fig. 1: FTIR spectra of KG

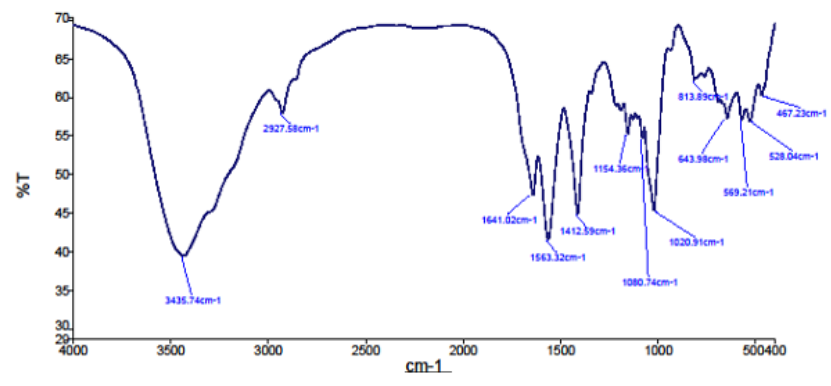

Fig. 2: FTIR spectra of CMKG

Table 1: Composition of formulations containing PHCL

\begin{tabular}{llllll}
\hline Formulation code & Propranolol HCl $(\mathrm{mg})$ & $\begin{array}{l}\text { HPMC K15 M } \\
(\mathrm{mg})\end{array}$ & $\begin{array}{l}\text { KG } \\
(\mathrm{mg})\end{array}$ & $\begin{array}{l}\text { CMKG } \\
(\mathrm{mg})\end{array}$ & Dip coatings with molten gelucire 43/01 \\
\hline $\mathrm{R}$ & 100 & 75 & 25 & - & - \\
$\mathrm{R} 1$ & 100 & 75 & 25 & - & One \\
$\mathrm{R} 2$ & 100 & 75 & - & 25 & One \\
$\mathrm{R} 3$ & 100 & 50 & - & 50 & One \\
\hline
\end{tabular}




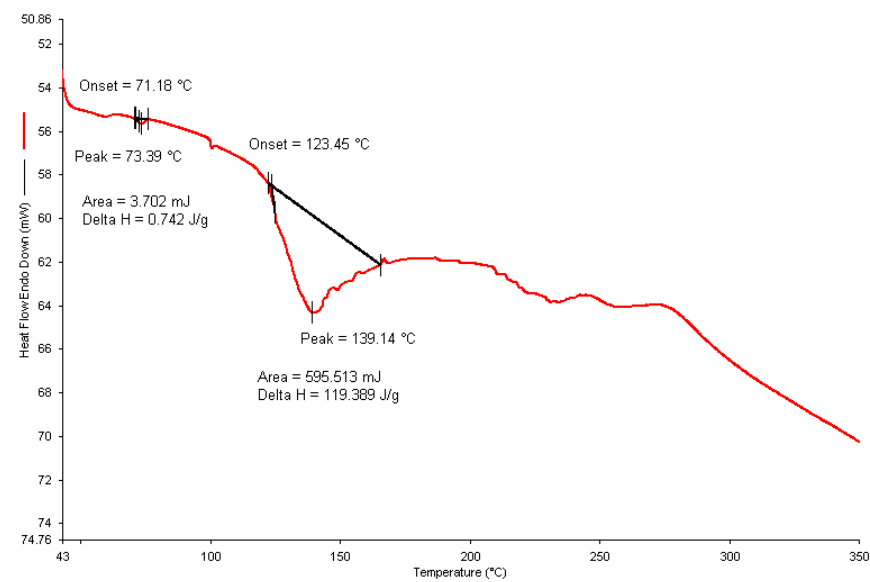

Fig. 3: DSC thermogram of KG

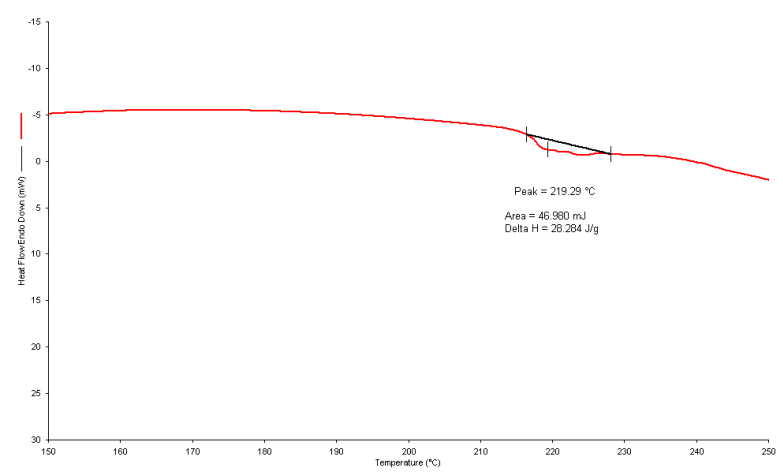

Fig. 3A: DSC thermogram of CMKG

Figs 3 and 3A exhibits the DSC thermograms of KG and CMKG. The thermal curve of KG showed a broad endotherm at $139^{\circ} \mathrm{C}$, attributed to the glass transition temperature of the polymer.

The DSC curve of CMKG (Fig. 3A) shows a broad endotherm at $219^{\circ} \mathrm{C}$. The shift in the endothermic peak indicates that modification of GG has taken place on carboxymethylation.

\section{${ }^{13}$ C NMR Spectra of KG}

The results of solid-state ${ }^{13} \mathrm{C}$ NMR spectra of carboxymethylated KG exhibited (Fig. 4) intense peaks at $\delta=181.818 \mathrm{ppm}$ [due to $\mathrm{C}=0$ (carboxylic acid moieties)]. The peak at $103.56 \mathrm{ppm}$ corresponds to $\mathrm{C} 1$ carbon in the $\beta$-glycosidic bond, while the broad signal at $82.05 \mathrm{ppm}$ (due to ring carbon of galactopyranose ring of KG. The signals of C5, C2, carbons are at 72.206 and 75.674. The peak at 60.923 is due to $-\mathrm{CH}_{2} \mathrm{OH}$. The signal at $21.748 \mathrm{ppm}$ is due to the acetyl residues in the polysaccharide. The signals at 25.11, 26.193, and 31.859 are due to aliphatic carbons.

The ${ }^{13} \mathrm{C}$ spectrum of KG was also recorded in a similar manner (spectra not shown). ${ }^{13} \mathrm{C}$ NMR spectra showed intense characteristic peaks at $\delta=101.2$ and $100.34 \mathrm{ppm}$ (due to anomeric carbons of $\mathrm{KG}$ ), at $82.023 \mathrm{ppm}$ (due to ring carbon of galactopyranose ring of $\mathrm{KG}$ ), at $71.84 \mathrm{ppm}$ (due to -C-O-C-bond of KG), and 23.39 and 19.66 ppm [due

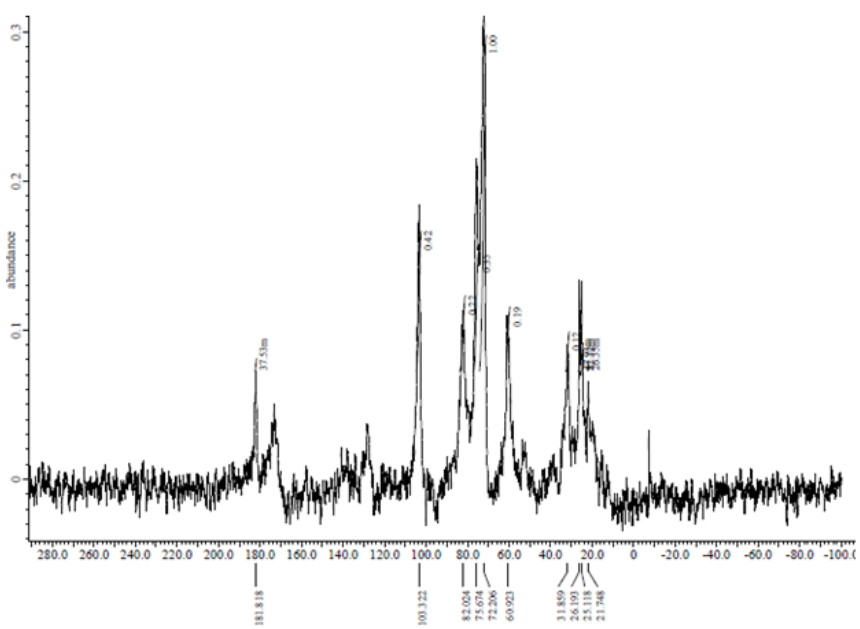

Fig. 4: ${ }^{13} \mathrm{C}$ spectra of CMKG

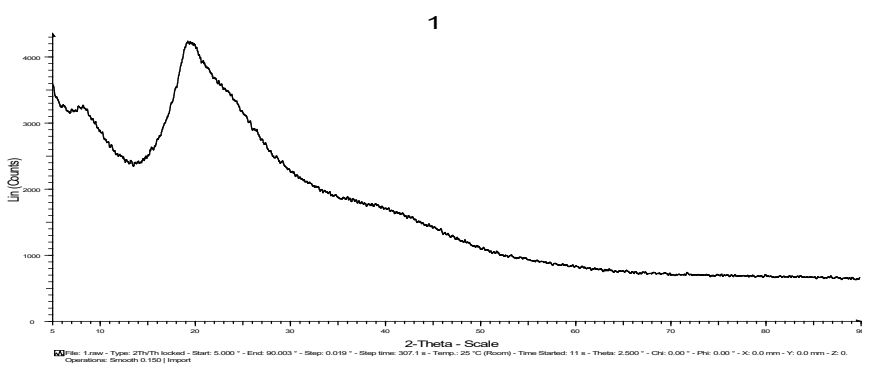

2

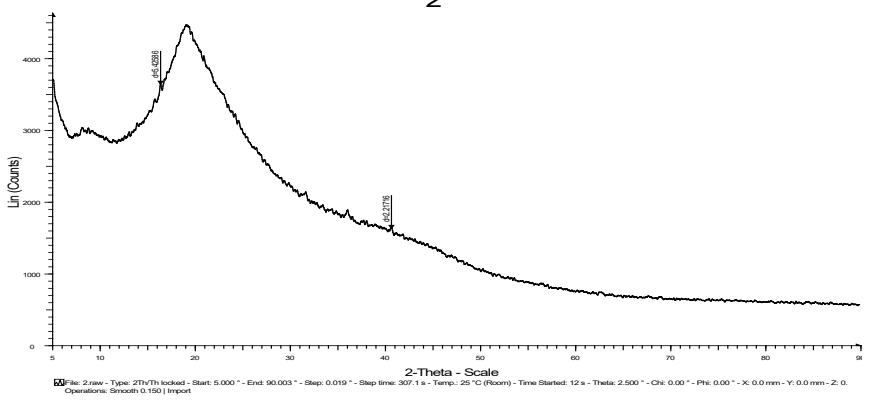

Fig. 5: X-ray diffractogram of (1) KG; (2) CMKG

to methyl carbon (CH3-) of rhamnose and acetyl residues in the KG]. ${ }^{[11]}$

Fig. 5 displays the X-ray diffraction pattern of KG and CMKG. The diffractogram of KG is typical of amorphous materials with no sharp peaks, while diffractogram of CMKG shows the typical characteristic peaks appearing at around 16 and $42^{\circ}$ ( $2 \theta$ scale), which indicates the increase in crystallinity of KG on carboxymethylation.

\section{Degree of Substitution}

The KG possesses numerous hydroxyl groups in its structure. The hydroxyl groups can be substituted with carboxymethyl groups by reacting in alkaline medium with monochloroacetic acid. From the degree of substitution, one can find how many hydroxyl groups are converted into carboxymethyl group. The reactivity of primary 
Table 2: Physicochemical attributes of HBS capsule formulations

\begin{tabular}{lllll}
\hline Formulation code & $\begin{array}{l}\text { Average fill per capsule } \\
(\mathrm{mg})\end{array}$ & $\begin{array}{l}\text { Average weight of filled } \\
\text { capsule }\end{array}$ & $\begin{array}{l}\text { Average weight of gelucire 43/01 } \\
\text { coated capsule }\end{array}$ & \% drug content \\
\hline R & $200 \pm 8.3$ & $302 \pm 7.6$ & $367 \pm 6.9$ & $99.82 \pm 3.76$ \\
R1 & $200 \pm 6.6$ & $304 \pm 5.6$ & $371 \pm 5.4$ & $99.18 \pm 3.11$ \\
R2 & $301 \pm 4.6$ & $368 \pm 7.1$ & $99.79 \pm 3.41$ \\
R3 & $200 \pm 6.9$ & $301 \pm 5.4$ & $372 \pm 6.8$ & $99.29 \pm 4.76$ \\
\hline
\end{tabular}

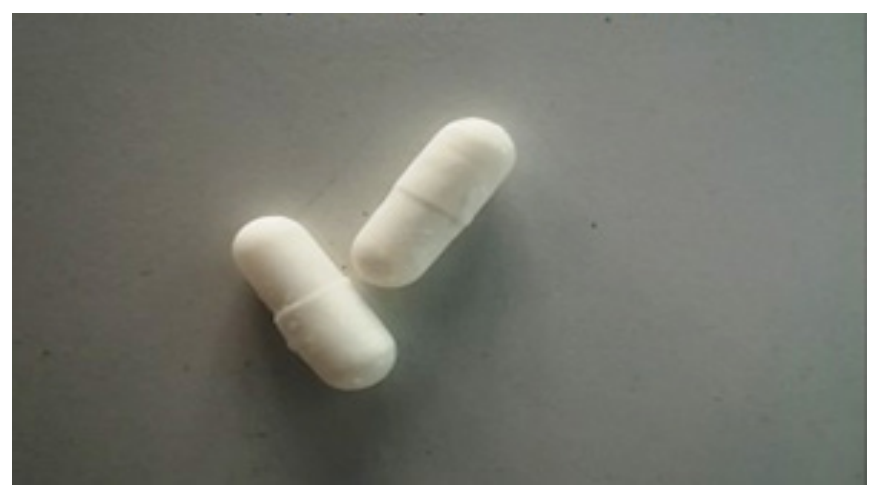

Fig. 6: Gelucire 43/01 coated HBS capsule formulations

hydroxyl is more than secondary hydroxyl groups; if we completely react three-hydroxyls, we will get the DS of "3." [16-19] The sample of CMKG was found to have degree of carboxymethyl substitution of $0.87 \pm 0.14$, as determined by classical acid-wash method.

\section{Development of HBS Capsule Formulations bearing PHCL}

\section{Selection of Model Drug}

Highly water-soluble drugs are very difficult to formulate into a sustained-release oral dosage form. The problem becomes more pronounced when the drugs exhibited an absorption window in upper gastrointestinal tract (GIT) or instability/ reduced solubility in the alkaline environment of small intestine. ${ }^{[22-24]}$ PHCL is such a medicinal agent. The drug showed pH-dependent solubility; at pH 1.2, the solubility of PHCL is $225 \mathrm{mg} / \mathrm{mL} .{ }^{[25]}$ For sustained stomach specific release of such drugs, it would be desirable to provide a drug delivery system that inherently has the property of extended gastric residence coupled with release retarding properties. Such a system will ensure the availability of the entire absorption window for highly soluble absorption window limited compounds or complete dissolution of drugs in the acidic environment of the stomach, thereby improving drug bioavailability. In the present investigation, an attempt has been made to study the feasibility of polymeric matrices composed of nonionic HPMC and CMKG as carriers for sustained stomach specific delivery of PHCL.

\section{Preparation of HBS Capsules}

Various HBS capsule formulations were prepared in two steps. In the first step, drug-polymer mix (Table 1) was

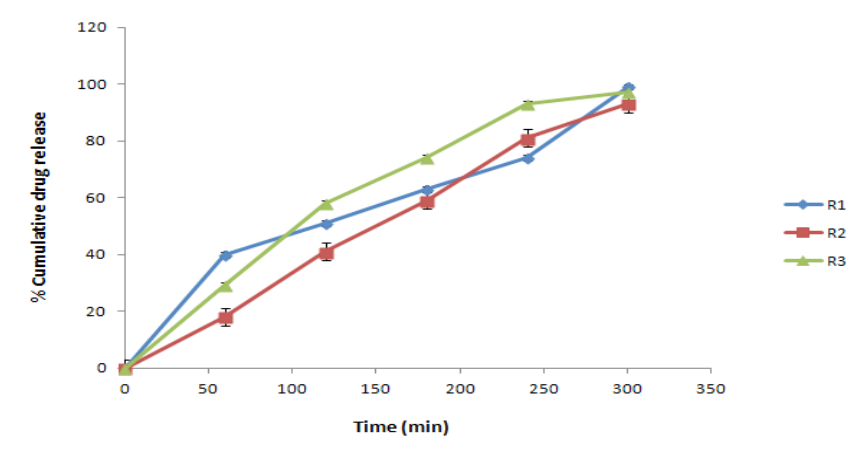

Fig. 7: \% cumulative drug release in $0.1 \mathrm{HCl}(\mathrm{pH} \mathrm{1.2)}$

encapsulated in hard gelatin capsule size 0 , using handoperated capsule filling machine. These filled capsules were then dip-coated by dipping into molten gelucire 43/01 (Fig. 6).

The lipid (gelucire 43/01) formed a thin hydrophobic coating around the capsules, which ultimately provides immediate buoyancy to the HBS formulations, when immersed in acidic dissolution medium. Few physicochemical attributes of HBS formulations are given in Table 2.

\section{In vitro Buoyancy and Drug Release Studies}

The in vitro buoyancy and drug release studies (Fig. 7) were performed in triplicate using USP (type II) dissolution apparatus at $50 \mathrm{rpm}$ in $900 \mathrm{~mL} 0.1 \mathrm{HCl}$ (pH 1.2) maintained at $37 \pm 0.5^{\circ} \mathrm{C}$.

With the exception of formulation $\mathrm{R}$, all other formulations (R1, R2, and R3) remained buoyant for the entire duration of release study. Formulation R composed of HPMC K15 M, KG, and the drug could not float for more than one hour and released almost $80 \%$ of drug before sinking in the acidic dissolution medium. This could be explained as propranolol is highly hydrophilic, which further reduces the strength of the aqueous gel layer due to high diffusional driving force and consequently increased erosion. As a result, hydrogel lost its integrity and became distorted, leading to burst release and premature sinking of the formulation. ${ }^{[26]}$ Considering the observation, in the present study, to improve the buoyancy and to address the problem of burst release, we have decided to coat the capsule formulations (R1, R2, and R3) with molten gelucire 43/01.

As a consequence, formulations R1, R2, and R3 remained floated on the dissolution medium for up to 6 hours. It was observed that as the HBS capsule formulations 
were put into dissolution medium, the lipid coating around the capsule begins to eroded, causing the penetration of dissolution medium inside the capsule shell leading to gel formation due to presence of hydrophilic polymer matrix (HPMC/KG or HPMC/CMKG). The whole system behaved like a lipid embedded polymeric raft, which floats over the surface of the dissolution medium and releases the drug slowly over an extended period of time. The purpose of adding dextrose and fructose to the formulation mix was to give impetus to the drug release from a lipid embedded hydrogel structure due to the generation of osmotic pressure. From formulation R1, about 40, 51, 74, and $99 \%$ drug was released at the end of $1 \mathrm{st}, 2 \mathrm{nd}, 4 \mathrm{th}$, and 6th hour, respectively. Here also, there was initial burst release of PHCL from the formulation. But later on, drug was released in an extended manner for up to 6 hours. This could be attributed to slow erosion of capsule shell due to lipidic coating, and consequently delayed penetration of dissolution medium inside the capsule. Up to 15 minutes, there was no drug release. After about 30 minutes, there was surge in drug release. This could be attributed to the fast disintegration of capsule shell due to rapid erosion of thinly coated lipid. The effect of dextrose and fructose on drug release is also not ruled out. These osmogens were added to impart osmotic pressure to the gel network. Once the capsule shell was completely disintegrated into pieces (beginning of 45th minute), the penetration of dissolution medium became relatively easy in the polymer matrix; this has caused not only the hydration of polymer but also dissolution of osmogens. Dissolution of osmogens has resulted in development of osmotic pressure within the partially formed gel network. Once the raft structure was fully formed, after about 60 minutes, the drug was released in a uniform manner for up to 6 hours. After that, formulations sank.

In case of formulation $\mathrm{R} 2$, the $\mathrm{KG}$ was replaced in the polymer matrix with equal amount of CMKG in the HBS capsules. From formulation R2, about 18, 59, 81, and $93 \%$ drug was released at the end of $1 \mathrm{st}$, 3rd, 4th, and 6 th hour, respectively. The drug release was statistically ( $p>0.05$ ) different from R1. This could be attributed to the controlled diffusion of drugs through the hydrophobichydrophilic polymeric raft, effectively countering the high diffusion driving force that might be exerted by highly hydrophilic PHCL.

In case of formulation R3, the CKG concentration was increased to $50 \mathrm{mg}$, drug release was increased compared to R1 and R2 ( $\mathrm{p}<0.05)$. From formulation R3, about 29, 58, 74 , and $93 \%$ drug was released at the end of 1 st, 2 nd, 3rd, and 4th hour, respectively. This could be attributed to the formation of highly hydrophilic drug-polymer gel due to increase in concentration of CKG, embedded in lipid raft; the drug release was modulated by osmogen and diffusion driving force exerted by the highly hydrophilic drug. This leads to a comparatively faster release of drug from the HBS capsules.

\section{Conclusions}

In this study, we have prepared and evaluated gelucire 43/01 coated HBS capsules for the sustained stomach specific delivery of highly hydrophilic model drug PHCL. In this study, three approaches were combined: for prolonged floating, coating of gelucire 43/01 on the hard gelatin capsules; release retardation by hydrophilic HPMC/KG or HPMC/CMKG based polymer matrix; and release facilitation by osmogens, dextrose, and fructose. Observations from this study suggested that all these approaches worked in conjunction and brought about a drug delivery system, which was not only capable of floating up to 6 hours but also retarded the release of the highly hydrophilic model drug. Another peculiarity of this work is that a very small amount of polymer was used in the polymer matrix. This polymer matrix formed a weak hydrogel upon exposure to dissolution medium, but the release retarding effect of the formed hydrogel was augmented by the hydrophobic gelucire $43 / 01$, and at the same time, osmogens prevented the excessive retardation of drug release by osmotic effect. We propose that the prepared HBS capsule formulation may constitute a potential carrier for sustained stomach specific release of hydrophilic drugs.

\section{ACKNOWLEDGMENT}

The authors thank Prof. M. P. Pandey, Vice-Chancellor of the IFTM University, and Dr. Reddy's Laboratories, India, for generosity.

\section{REFERENCES}

1. Song R, Murphy M, Li C, Ting K, Soo C, Zheng Z. Current development of biodegradable polymeric materials for biomedical applications. Drug Des Devel Ther. 2018;12:3117-3145.

2. Vroman I, Tighzert L. Biodegradable Polymers. Materials (Basel). 2009;2(2):307-344.

3. Kaczmarek B, Sionkowska A. Drug release from porous matrixes based on natural polymers. Curr Pharm Biotechnology. 2017;18(9):721-729.

4. Rana V, Rai P, Tiwary AK, Singh RS, Kennedy JF, Knill CJ. Modified gums: Approaches and applications in drug delivery. Carbohydr Polym. 2011;83:1031-1047.

5. Chauhan, GS, Dhiman SK, Guleria LK, Kaur I. Polymers from renewable resources: kinetics studies of the radiochemical graft copolymerization of styrene onto cellulose extracted from pine needles and the effect of some additives on the grafting parameters in an aqueous medium. J Appl Polym Sci. 2002;83:1490-1500.

6. Okieimen FE. Grafting ethyl methacrylate onto partially hydrolysed starch using ceric ion as initiator. Indian J ChemTechnol. 2003;10:197-200.

7. Singh V, Tiwari A, Tripathi DN, Sanghi R. Microwave assisted synthesis of guar-g-polyacrylamide. Carbohydr Polym. 2004;58: 1-6.

8. Chan AW, Whitney RA, Neufeld RJ. Semi synthesis of a controlled stimuli-responsive alginate hydrogel. Biomacromolecules. 2009;10:609-616.

9. Božanić DK, Trandafilović LV, Luyt AS, Djoković V. 'Green' synthesis and optical properties of silver-chitosan complexes and nanocomposites. React. Funct. Polym. 2010;70:869-873.

10. Sarathchandiran I, Suresh Kumar P. Characterization and 
standardization of gum karaya. International Journal of Biopharmaceutics. 2014;5:142-151.

11. Bahulkar SS, Munot NM, Surwase SS. Synthesis, characterization of thiolated karaya gum and evaluation of effect of $\mathrm{pH}$ on its mucoadhesive and sustained release properties. Carbohydr Polym. 2015;130:183-190.

12. Padil VV, Senan C, Černík M. Dodecenylsuccinic anhydride derivatives of gum karaya (Sterculia urens): preparation, characterization, and their antibacterial properties. J Agric Food Chem. 2015;63(14):3757-3765.

13. Alange VV, Birajdar RP, Kulkarni RV. Functionally modified polyacrylamide-graft-gum karaya $\mathrm{pH}$-sensitive spray-dried microspheres for colon targeting of an anti-cancer drug. Int J Biol Macromol. 2017;102:829-839.

14. Chakravorty A, Barman G, Mukherjee S, Sa B. Effect of carboxymethylation on rheological and drug release characteristics of locust bean gum matrix tablets. Carbohydr Polym. 2016;144:5058.

15. Bhatia M, Ahuja M. Psyllium arabinoxylan: carboxymethylation, characterization and evaluation for nanoparticulate drug delivery. Int J Biol Macromol. 2015;72:495-501.

16. Eyler RW, Klug ED, Diephus F. Determination of Degree of Substitution of Sodium Carboxymethylcellulose. Anal. Chem. 1947;19:24-27.

17. Ahuja M, Singh S, Kumar A. Evaluation of carboxymethyl gellan gum as a mucoadhesive polymer. Int J Biol Macromol. 2013;53:114-121.

18. Silva DA, Paula RCMde, Feitosa JPA, Brito ACFde, Maciel JS, Paula HCB. Carboxymethylation of cashew tree exudate polysaccharide.
Carbohydr Polym. 2004;58:163171.

19. Kaity S, Ghosh A. Carboxymethylation of locust bean gum: application in interpenetrating polymer network microspheres for controlled drug delivery. Ind Eng Chem. 2013;52(30):1003310045.

20. Tijsen CJ, Scherpenkate HJ, Stamhuis EJ, Beenackers AACM. Optimization of the Process Conditions for the Modification of Starch. Chem Eng Sci. 1999;54:2765-2772.

21. Sethi S, Kaith BS, Kaur M, Sharma N, Khullar S. Study of a crosslinked hydrogel of Karaya gum and Starch as a controlled drug delivery system. J Biomater Sci Polym Ed. 2019;30(18):1687-1708.

22. Mohammad H, "Gastroretentive drug delivery system comprising an extruded hydratable polymer," EP 1513508 B1, Euro-Celtique S.A., 2014.

23. Masaru T, Kazuhiro S, Erika K, Shingo K, Takashi H, Kazuki F. Design of biocompatible and biodegradable polymers based on intermediate water concept. Polym J. 2015;47(2):114-121.

24. Hunkeler D, Eichler K, Arnold J. Gastroretentive drug delivery system for controlled drug release in the stomach and into the upper intestines, US 20130315991 A1, Aqua+Tech Specialties, La Plaine, Switzerland, 2013.

25. Takka S, Rajbhandari S, Sakr A. Effect of anionic polymers on the release of propranolol hydrochloride from matrix tablets. Eur J Pharm Biopharm. 2001;52(1):75-82.

26. Dubey J, Verma A, Verma N. Evaluation of chitosan based polymeric matrices for sustained stomach specific delivery of propranolol hydrochloride. Indian Journal of Materials Science. 2015;2015.

HOW TO CITE THIS ARTICLE: Verma A, Sachan N, Verma A. Carboxymethylation of karaya gum: application in gastroretentive drug delivery for sustained release of model drug. Int. J. Pharm. Sci. Drug Res. 2020;12(3):300-306. DOI: 10.25004/IJPSDR.2020.120314 